\title{
Land Use Classification and Change Detection Using Multi-temporal Landsat Imagery in Sulaimaniyah Governorate, Iraq
}

\author{
Karwan Alkaradaghi, Salahalddin S. Ali, Nadhir Al-Ansari, and Jan Laue
}

\begin{abstract}
Rapid growth in urbanized areas is a worldwide phenomenon. The rate of urban growth is very fast in developing countries like Iraq. This study illustrated urbanized area development in Sulaimaniyah Governorate from 2001 to 2017 using different Landsat imagery, Landsat Thematic Mapper (TM) and Landsat Operational Land Imager (OLI). The Environment for visualizing images ENVI 5.3 and GIS software was utilized for image pre-processing, calibration and classification. The Maximum likelihood method was used in the accurately extracted solution information from geospatial Landsat satellite imagery of different periods. The Landsat images from the study area were categorized into six different classes. These are: forest, vegetation, rock, soil, built up and water body. Land cover variation and land use change detection in the area were calculated for over a 17 year period. The Change detection Analysis shows an explosive demographic shift in the urban area with a record of $+8.99 \%$ which is equivalent to $51.80 \mathrm{~km}^{2}$ over a 17 years period and the vegetation area increased with $214 \mathrm{~km}^{2}$. On the other hand, soil area was reduced by $257.87 \mathrm{~km}^{2}$. This work will help urban planners in the future development of the city.
\end{abstract}

K. Alkaradaghi · N. Al-Ansari $(\bowtie) \cdot J$. Laue

Lulea University of Technology, 97187 Lulea, Sweden

e-mail: nadhir.alansari@ltu.se

K. Alkaradaghi · S. S. Ali

Department of Geology, College of Science, Sulaimani

University, Sulaimaniyah, 460013, Iraq

e-mail: salah.saeed@komar.edu.iq

\section{K. Alkaradaghi}

Kurdistan Institution for Strategic Studies and Scientific

Research, Sulaimaniyah, 460013, Iraq

S. S. Ali

Komar University of Science and Technology,

Sulaymaniyah, Iraq

\section{Keywords}

Landsat - Land use land cover (LULC) •

Maximum likelihood classification (MLC) •

Change detection - ArcMap

\section{Introduction}

Land use land cover LULC change detection is commonly referred to as the modification of earth surface through human activities for decent urban management [1]. There is no doubt that population density growth and economic development play an important role in land cover change, thus, resulting in an observable pattern in the LULC over the time [2]. Nowadays, the rapid urbanization rate in most of developing countries is the priority of global problems; however, this mutation has a significant impact on future environment and urban planning processes [3].

Sulaimaniyah Governorate like the rest of the Kurdistan region of Iraq has faced rapid expansion in last 17 years in the urbanized area due to high population growth and economic prosperity [4]. Remote sensing and ArcMap software are the main applications applied in direct desktop mapping for temporal analysis and quantification of change in LULC with a better accuracy and low cost $[5,6]$.

Landsat data enhanced different imageries in the world with the ability of frequent revisits. Satellite images classification for the same area over the time affects the change in the area classes according to vegetation growth and welting on the bare soil. However, all the selected satellite images in this study refer to the same season over the years to avert detecting false changes in the land cover due to vegetation phenology $[7,8]$.

The Maximum likelihood is a supervised classification method that was used in this study to detect LULC change to show how land use has been changed from 2001 to 2017. Each pixel in the classified Landsat images varies according to land cover changes over the time [2]. 
Iraq witnessed successive wars in the past that affected its economic, urban and human recession all over the country including Sulaymaniyah city. According to food security and vulnerability in an in-depth survey of Sulaimaniyah Governorate after the events in 2003, Iraq witnessed a huge economic boom, Sulaimaniyah's economy today relies on tourism, agriculture, factories, trade and construction development [8].

There is no doubt that urban development affects the environment and global climate by losses in vegetation biomass, deforestation and land use change from areas with high probability of urban expansion [9].

This study is an attempt to assess the status of LULC change through the built up development in Sulaimaniyah governorate to detect the rate of land use and the changes that have occurred over the past two decades using geospatial techniques.

\section{Study Area}

Sulaimaniyah city is one of the three major urban cities of Kurdistan Region. Sulaimaniyah Governorate is located at the North East of Iraq (Fig. 1). Geographically, the city bounded by mountains in the northeast and situated in lower land that covers an area of around $470 \mathrm{~km}^{2}$ with a total population of 829,245 people in early 2017 according to the data achieved from Statistical Directorate in Sulaimaniyah. The study area is characterized by a distinct continental interior climate of the Mediterranean type with the average annual precipitation ranging from 500 to $700 \mathrm{~mm}$.

\section{Data and Methodology}

Landsat 5 Thematic Mapper (TM) of the years 2001, 2007, 2010 and 2011 were used with Landsat 8 Operational Land Imager (OLI) of 2016 and 2017 for LULC classification and all the available images were selected for the same season. The city plan collected from the Sulaimaniyah municipality as a shapefile of the study area extraction. In this study, the remote sensing software ENVI 5.3 for image processing was used. During the process, the imagery was geometrically corrected through pre-processing calibration, which consisted in atmospheric and topographic correction [10, 11]. The image-processing techniques are statistical algorithms that change the visual appearance or geometric properties of the images, These corrections are required for selected multitemporal or multisensor Landsat images to improve visibility appearance and image quality and to get more accurate results $[10,11,12]$. In Landsat Operational Land Imager (OLI), digital number values were converted to the surface reflectance with the fast line-of-sight atmospheric analysis of hypercubes (FLAASH) to remove atmospheric effects and create a surface reflectance image.

The pre-processed images were classified considering a supervised classification method. In this technique, we chose the maximum likelihood which is based on Bayesian theory in estimating parameters of a probabilistic model [13]. Each pixel is assigned to a class according to its probability. The Mean vector and covariance metrics are the key components of maximum likelihood classification that can be retrieved from a training data (signatures or region of interest ROI) $[5-8,14]$.
Fig. 1 Location map of the study area

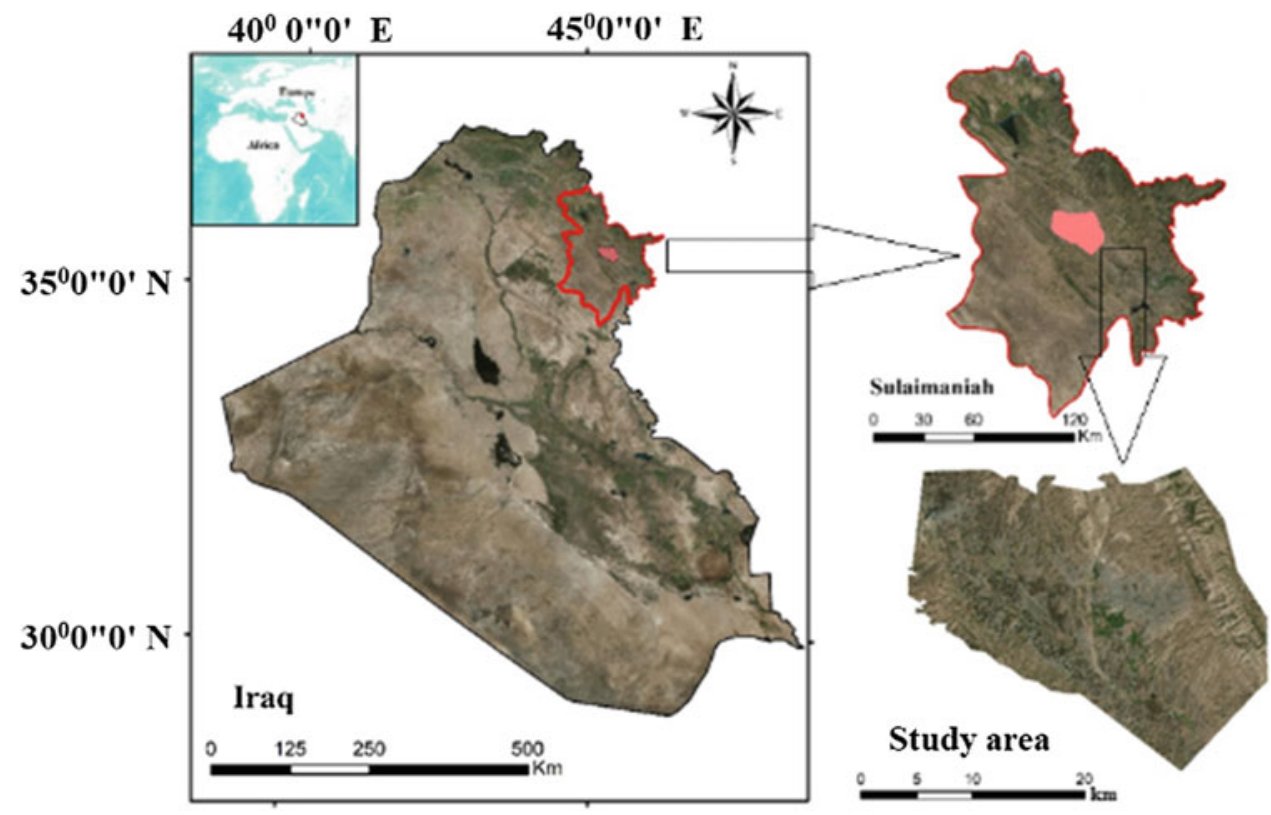


Change detection in an area was calculated for each class separately according to the pixel geometry and statistical distribution of the pixels through the study area.

\section{Results}

\subsection{Classification Results}

Six land cover classes were identified from MLC. These are forests, built up area, rock, soil, vegetation and water bodies. The MLC in the Sulaimaniyah Governorate in 2001 and 2017 are shown in Fig. 2.

Change detection in the area was calculated for different LULC categories using MLC raster image and pixel geometry. The change detections in different LULC categories in the Sulaimaniyah Governorate from 2001 to 2017 are illustrated in Table 1.

\subsection{Change Detection Analysis}

During the 17 years (2001-2017), the built-up area has increased by $9 \%$ which represents $51.80 \mathrm{~km}^{2}$. On the other hand, the soil area decreased by $44.77 \%$. Rock, forest and water body recorded minimal change while vegetation increased by over 37\% (Fig. 3a and Table 1). The Built-up area increased from $3.87 \%$ area in 2001 to reach $12.87 \%$ in 2017 (Fig. 3b).

\section{Discussion}

To produce a series of land use classification maps, all satellite images, taken in the same season, were selected over the years. The only time difference in acquisition date was that of the first image which was taken in 20011 month earlier. Thus, vegetation appears not to cover all the area from the
Fig. 2 Maximum likelihood classification (MLC) in the Sulaimaniyah governorate (2001 and 2017)
Table 1 Change detection in different LULC categories in the Sulaimaniyah governorate from 2001 to 2017

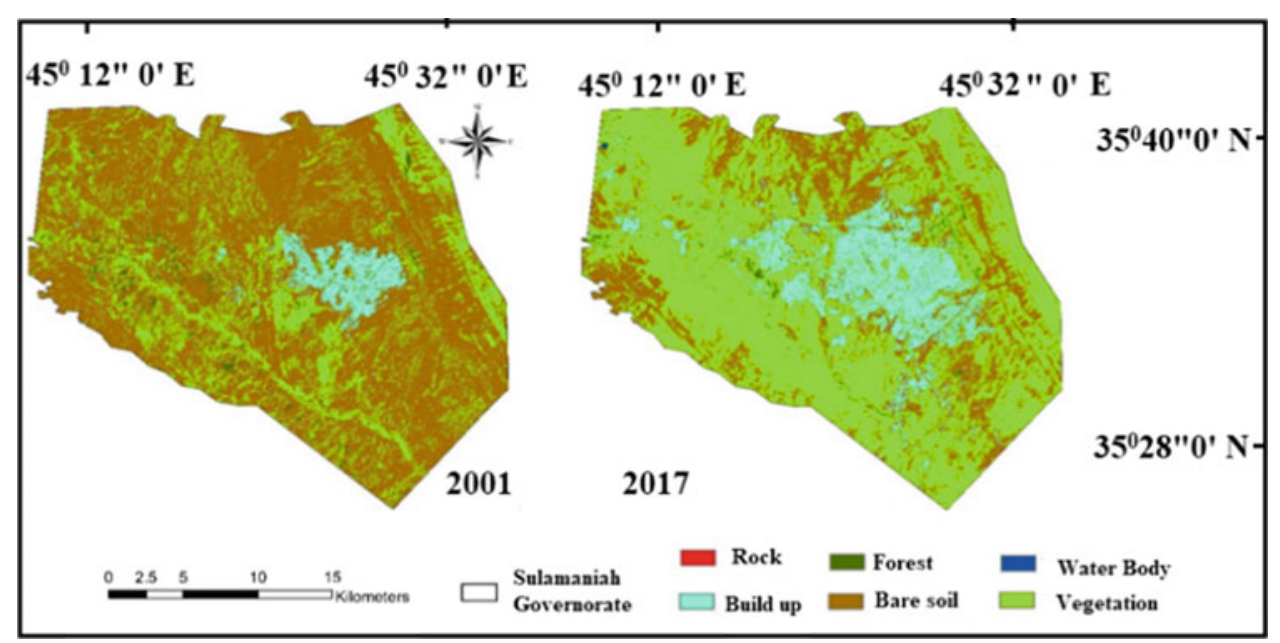

\begin{tabular}{l|l|l|l|l|l|l|l|l}
\hline $\begin{array}{l}\text { Classified } \\
\text { area }\end{array}$ & $\begin{array}{l}\% \\
\text { area } \\
2001\end{array}$ & $\begin{array}{l}\% \\
\text { area } \\
2007\end{array}$ & $\begin{array}{l}\% \\
\text { area } \\
2010\end{array}$ & $\begin{array}{l}\% \\
\text { area } \\
2011\end{array}$ & $\begin{array}{l}\% \\
\text { area } \\
2016\end{array}$ & $\begin{array}{l}\% \\
\text { area } \\
2017\end{array}$ & $\begin{array}{l}\text { Change } \\
\text { detection } \\
\text { in } \%\end{array}$ & $\begin{array}{l}\text { Change } \\
\text { detection in } \\
\mathrm{km}^{2}\end{array}$ \\
\hline Rock & 0.66 & 0.66 & 0.05 & 0.05 & 0.03 & 0.03 & -0.63 & -3.61 \\
\hline $\begin{array}{l}\text { Built up } \\
\text { area }\end{array}$ & 3.87 & 8.74 & 9.08 & 9.29 & 12.86 & 12.86 & +8.99 & +51.80 \\
\hline Forest & 1.62 & 1.02 & 8.55 & 1.89 & 0.84 & 0.84 & -0.78 & -4.51 \\
\hline Soil & 67.56 & 48.55 & 21.70 & 29.04 & 22.79 & 22.79 & -44.77 & -257.87 \\
\hline $\begin{array}{l}\text { Water } \\
\text { bodies }\end{array}$ & 0.02 & 0.02 & 0.03 & 0.04 & 0.05 & 0.05 & +0.03 & +0.16 \\
\hline Vegetation & 26.29 & 41.69 & 60.60 & 1.89 & 63.45 & 63.45 & +37.16 & +214.03 \\
\hline
\end{tabular}



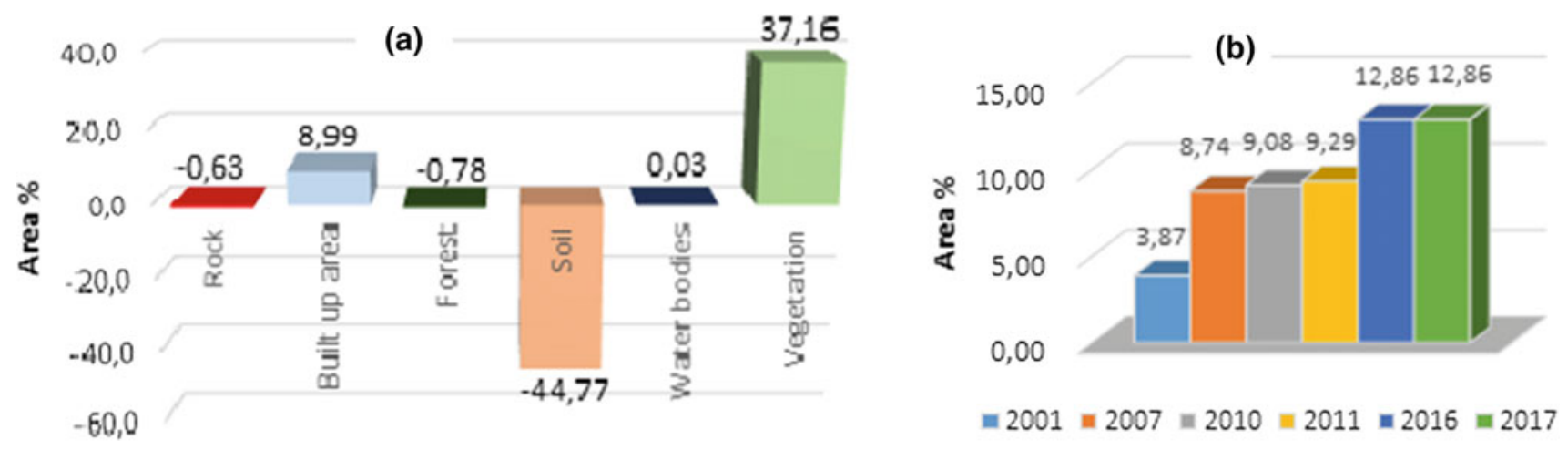

Fig. 3 a LULC change in area percentage from the 2001 to 2017. b Change in build up area percentage from 2001 to 2017

beginning which causes false changes in the land cover due to phenology [7, 8]. Classification results have shown that MLC is the robust technique and there are fewer chances of misclassification. In situations of rapid land use change, the classified images provide detailed information to understand the LULC. Observations of the earth from space provide objective crucial information to understand the influence of human activities within the urban area over time [3].

LULC studies are much salutary for future urban planners to guaratee a sustainable city development.

\section{Conclusions}

This study shows the LULC status for the period 2001-2017 with the view of change detection in land area. According to the results, urbanism recorded $51.80 \mathrm{~km}^{2}$ expansion. This expansion occurs with soil, rock and forest shortage in area by $257.87,3.61$ and $4.51 \mathrm{~km}^{2}$ respectively by the end of 2017. The water body and vegetation increased by 0.16 and $214.03 \mathrm{~km}^{2}$ respectively.

The population density growth and economic development play an important role in land cover change. This work will help urban planners and decision makers with future plans of the city.

\section{References}

1. Comber, A.J.: Land use or land cover? J. Land Use Sci. 3(4), 199_ $201(2008)$

2. Liu, J., Heiskanen, J., Aynekulu, E., Pellikka, P.K.E.: Seasonal variation of land cover classification accuracy of landsat 8 images in Burkina Faso. Int. Arch. Photogrammetry, Remote Sens. Spat. Info. Sci.-ISPRS Arch. 40(7W3), 455-460

3. Rawat, J.S., Kumar, M.: Monitoring land use/cover change using remote sensing and GIS techniques: a case study of Hawalbagh block, district Almora, Uttarakhand, India. Egypt. J. Remote Sens. Sp. Sci. 18(1), 77-84 (2015)

4. Eklund, L., Abdi, A., Islar, M.: From producers to consumers: the challenges and opportunities of agricultural development in Iraqi Kurdistan. Land 6(3), 44 (2017)

5. Blaschke, T., Hay, G.J., Weng, Q., Resch, B.: Collective sensing: integrating geospatial technologies to understand urban systems-an overview. Remote Sens. 3(8), 1743-1776 (2011)

6. Kachhwala, T.S.: Temporal monitoring of forest land for change detection and forest cover mapping through satellite remote sensing. Proc. 6th Asian Conf. Remote Sens. 77-83 (1985)

7. Weil, G., Lensky, I.M., Resheff, Y.S., Levin, N.: Optimizing the timing of unmanned aerial vehicle image acquisition for applied mapping ofwoody vegetation species using feature selection. Remote Sens. 9(11) (2017)

8. Planning, M.O.F., Cooperation, D., Health, M.O.F.: Comprehensive food security and vulnerability analysis in Iraq. Methodology (2008)

9. Seto, K.C., Christensen, P.: Remote sensing science to inform urban climate change mitigation strategies. Urban Clim. 3, 1-6 (2013)

10. Song, C., Woodcock, C.E., Seto, K.C., Lenney, M.P., Macomber, S.A.: Classification and change detection using Landsat TM data: when and how to correct atmospheric effects? Remote Sens. Environ. 75(2), 230-244 (2001)

11. Schulz, J.J., Cayuela, L., Echeverria, C., Salas, J., Rey Benayas, J. M.: Monitoring land cover change of the dryland forest landscape of central Chile (1975-2008). Appl. Geogr. 30(3), 436-447 (2010)

12. Robert, A.S.: Remote Sensing: Models and Methods for Image Processing, vol. 95, no. 1 (2012)

13. Rosenfield, G.H., Fitzpatrick-Lins, K.: A coefficient of agreement as a measure of thematic classification accuracy. Photogramm. Eng. Remote Sens. 52(1979), 223-227 (1986)

14. Wu, C., et al.: Land surface phenology derived from normalized difference vegetation index (NDVI) at global FLUXNET sites. Agric. For. Meteorol. 233, 171-182 (Dec 2016) (2017) 